\title{
HYDROGEN HYBRID MACHINE
}

\author{
Mrs.Ramya.D ${ }^{1}$, Dr.Rani Fathima Kamal Basha ${ }^{2}$, and Dr.Bharathi M.L ${ }^{3}$ \\ \{ramya.devasahayam@gmail.com ${ }^{1}$,dr.ranifathima@gmail.com, ${ }^{2}$ bharathiml15@gmail.com ${ }^{3}$ \}

\begin{abstract}
Assistant Professor, Sathyabama Institute of Science and technology,Chennai,India ${ }^{1}$, Lecturer,Al Musanna college of Technology Al Mulladah sultanate of oman ${ }^{2}$,
\end{abstract} \\ Assistant Professor, Sathyabama Institute of Science and technology,Chennai,India ${ }^{3}$
}

\begin{abstract}
This work is focuses on the working system, which runs on both mechanical energy (engine), and electrical energy (motor) andto conserve fuel in tank by using the sustainable resource hydrogen thus the system will be working on hydrogen, petrol and $\mathrm{Ni}$ Mh cell. As a result, to make a working system which runs on both mechanical energy (engine) and electrical energy (motor) $[1,2,3,4]$
\end{abstract}

Keywords:Inductionmotor,Currentsignatureanalysis(CSA),Voltagesignatureanalysis(VSA),motors ignature analysis(MCSA)

\section{Introduction}

This work is focused on conserving resources using hydrogen fueled machine which can run on fuel such as petrol and hydrogen as well on electricity, where the motor generates the torque for the wheels to move. This machine in fig. 1 as we have built contains different type's machineries, which are used for creating a hybrid environment. The Engine is used for combustion, whichin turn starts the machine. Alternatively, we can also start the machine by using the electric motor.

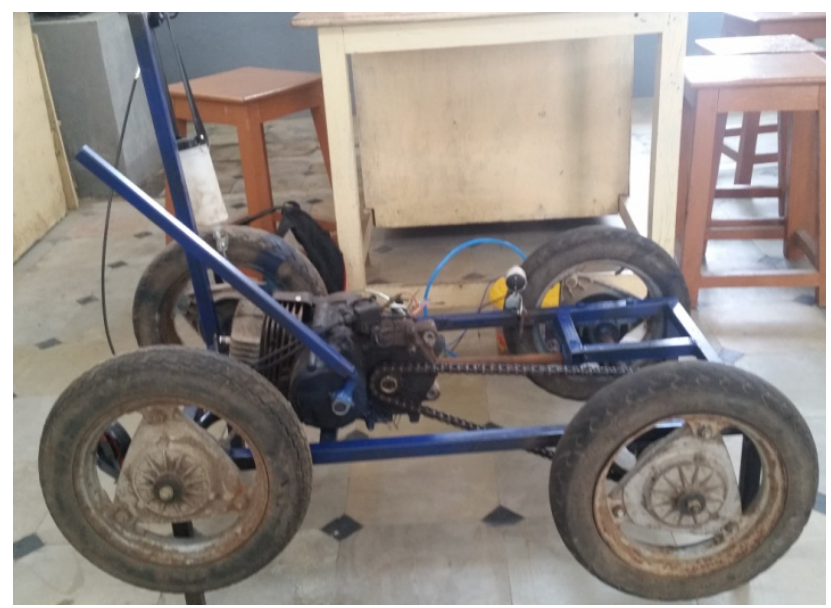

Fig.1.Hydrogen Hybrid Machine

Hydrolysis is done using rods dipped in salt water with catalyst as baking soda. As for the electric motor, the battery supplies the sufficient current required for it to operate.

The gear chain is used to drive the wheels as well as regenerate electricity by coupling with the help of a dynamo attached.

\section{BASIC PROCEDURE}

The multi fuel engine apparatus consists of an electrolyte, cathode, anode, battery, carburetor, engine and gearbox. The water is supplied to electrolyte. The electrolyte setup consists of cathode and anode. The current from battery is supplied to electrolyte setup to the cathode and anode, which converts the water flowing through it into oxygen, and hydrogen, which are made to pass through different tubes to the carburetor. The carburetor uses oxygen and hydrogen simultaneously with the fuel to increase the performance of the engine and reduce the emission. In addition, the motor is used for drive the rear wheel of the vehicle, so that it is called hydrogen - hybrid vehicle. $[5,6,7]$ 


\section{HYDROLYSIS}

Hydrogen on demand hybrid we are taking a distilled water with one teaspoon of baking soda used as catalyst. We are supplying $12 \mathrm{v}$ of electricity, which separates the hydrogen from oxygen.

Hydrogen Commercialization

HOD $=$ Hydrogen on demand, no need for storage of hydrogen gas

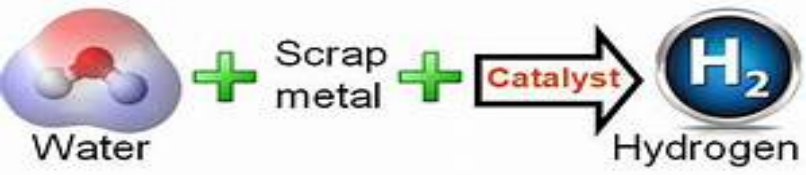

Fig.2.Hydrogen Commercialization

\section{Electrolysis: Splitting water with electricity to produce hydrogen and oxygen:}

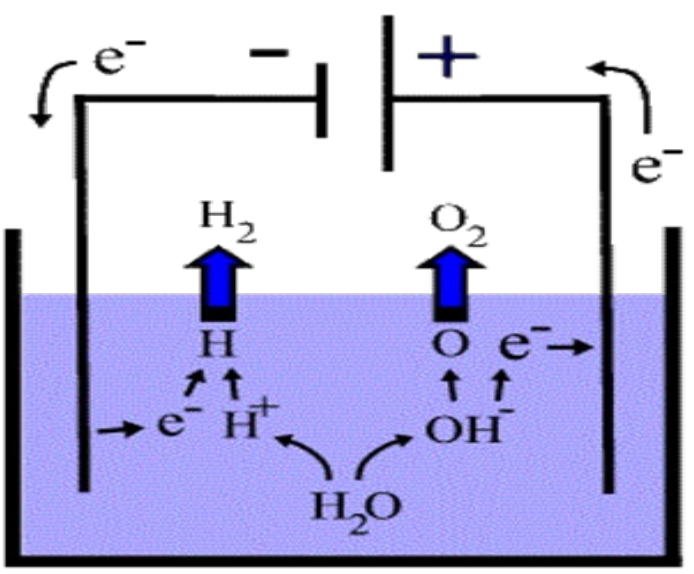

Fig.3.Electrolysis

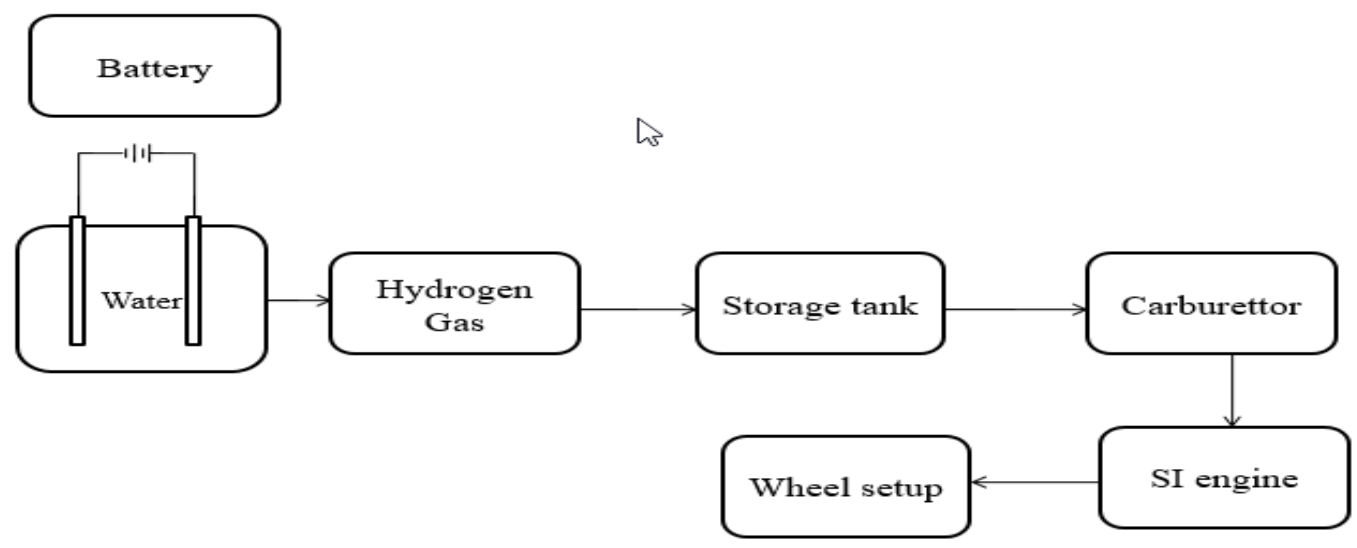

Fig.4.Layout of electrolysis process

\section{ANALYSIS ON ELECTROLYSIS}


The analysis in fig.2,3 \&4 provides us a brief summary on the level of voltage that is required for the breakdown water to produce hydrogen and oxygen, which helps in the generation of electricity

Minimum voltage $1.23 \mathrm{v}$.

1 Litre of water $=111.19 \mathrm{~g}$ of hydrogen $+888.81 \mathrm{~g}$ of oxygen.

$36.0012 \mathrm{~kg}$ atomic weight of water gives $4.0032 \mathrm{~kg}$ ofhydrogen and $31.998 \mathrm{~kg}$ of oxygen.

Therefore, a 1kilo will give $4.0032 / 36.0012=111.19 \mathrm{gm}$ of hydrogen

$31.998 / 36.0012=888.81 \mathrm{gm}$ of oxygen.

We will get two hydrogen for every oxygen thus; we get twice the hydrogen molecule.

Anode +ve $6 \mathrm{H} 2 \mathrm{O}(\mathrm{l})-->\mathrm{O} 2(\mathrm{~g})+4 \mathrm{H} 3 \mathrm{O}+(\mathrm{aq})+4 \mathrm{e}-($ toanode) $\mathrm{b}$ $\mathrm{E}^{\circ}=+1.229 \mathrm{~V}, \mathrm{pH} 0 \mathrm{~d} \quad \mathrm{E}^{\circ 1}=+0.815$ V.Cathode $\quad$-ve $\quad 4 \mathrm{e}$-(from cathode) $+4 \mathrm{H} 2 \mathrm{O}(\mathrm{l})$--

$>2 \mathrm{H} 2(\mathrm{~g})+4 \mathrm{OH}-(\mathrm{aq})$

$\mathrm{E}^{\circ}=-0.828 \mathrm{~V}, \mathrm{pH} 14 \quad \mathrm{E}^{\mathrm{ol}}=-0.414 \mathrm{~V}$

\section{ENGINE}

2-stroke engines get heated up very quickly and waste lots of heat energy. For that, we need something to carry out the wasted heat. For this, mixing oil in the fuel increases the net specific heat and helps in maintaining the heat.[8]

\section{MOTOR}

We are using a high torque brushless dc motor

Specifications:

Voltage: $12 \mathrm{~V}-24 \mathrm{~V}$

Current: 5 amps

Watts:20-60watts

\section{DYNAMO}

Output power $(\mathrm{W})-0.56$

Output Volt $-(\mathrm{V})-6 \mathrm{~V}$

Output Current $-0.126 \mathrm{~A}$

\section{WORKING}

File Naming the multi fuel engine apparatus consists of an electrolyte, cathode, anode, battery, carburetor, engine and gearbox. The water is supplied to electrolyte. The electrolyte setup consists of cathode and anode. The current from battery is supplied to electrolyte setup to the cathode and anode, which converts the water flowing through it into oxygen, and hydrogen, which are made to pass through different tubes to the carburetor.

The carburetor uses oxygen and hydrogen simultaneously with the fuel to increase the performance of the engine and reduce the emission. In addition, the motor is used for drive the rearwheel of the vehicle, so that it is called hydrogen - hybrid vehicle.

The carburetor works on Bernoulli's principle

\section{Battery}

Battery is mainly used to charge the motor and to make it run for an extended time.

Voltage: $12 \mathrm{~V}$

Current: 7 amps

Battery Analysis

Running time (h) =battery capacity (mah)

Operatingcurrent (ma)

Backup time $=$ Vout*ah/output(W)

Charging time of the battery $=$

Battery Ah/Charging Current

Discharging $=$ Battery Ah*BatteryVolt/Applied Load

TableI: Performance table 


\begin{tabular}{|l|l|l|}
\hline S1. No & Parameters & values \\
\hline 1 & Displacement & $69.9 \mathrm{cc}$ \\
\hline 2 & No. of Cylinders & 1 \\
\hline 3 & No. of Gears & 1 \\
\hline 4 & Maximum Power & 3.5 Bhp@ 5000 rpm \\
\hline 5 & Maximum Torque & 5.0 Nm @ 3750 rpm \\
\hline 6 & Engine Description & 2 Stroke, Single Cylinder \\
\hline
\end{tabular}

If the Dc motor is $12 \mathrm{v}$ has $3 \mathrm{amps}$ then it is $36 \mathrm{~W}$. If we connect to a $12 \mathrm{v}$ battery with $75 \mathrm{amps}$ per hr we get $12 * 75=900 \mathrm{~W} / 36=25 \mathrm{hrs}$, the torque of the Motor would shrink some of the $25 \mathrm{hrs} .75 \mathrm{amps}$ in an hr is max so if a motor in an average draws 1.5 amps and run continuously then it should run for $75 / 1.5=50 \mathrm{hrs}$.

\section{Existing System}

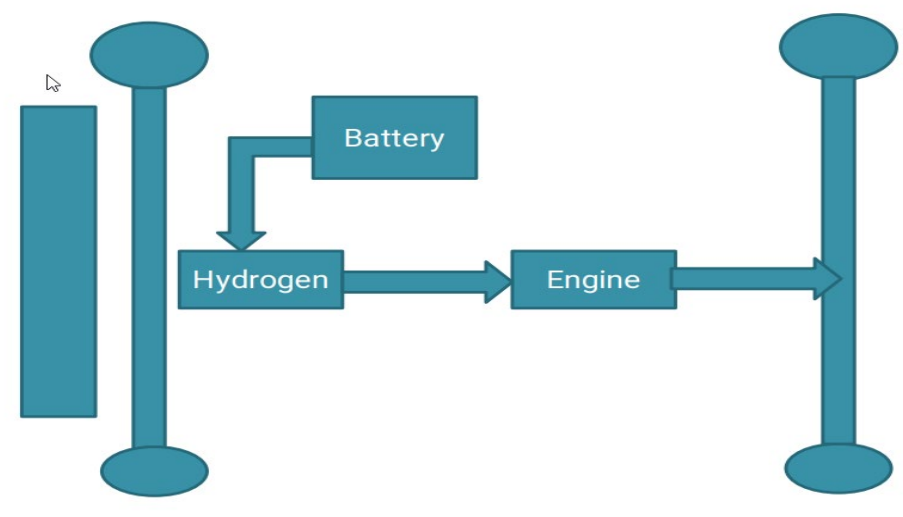

Fig.5.Existing block diagram

The existing system shown in fig.5. uses hydrogen supported with a battery. Where the power generated is then transferred to the engine, which then made to move the wheels through the gear chains and couplings. In this system, inclusion of motor was not possible thus; the status hydrogen could not be achieved.

Proposed System 

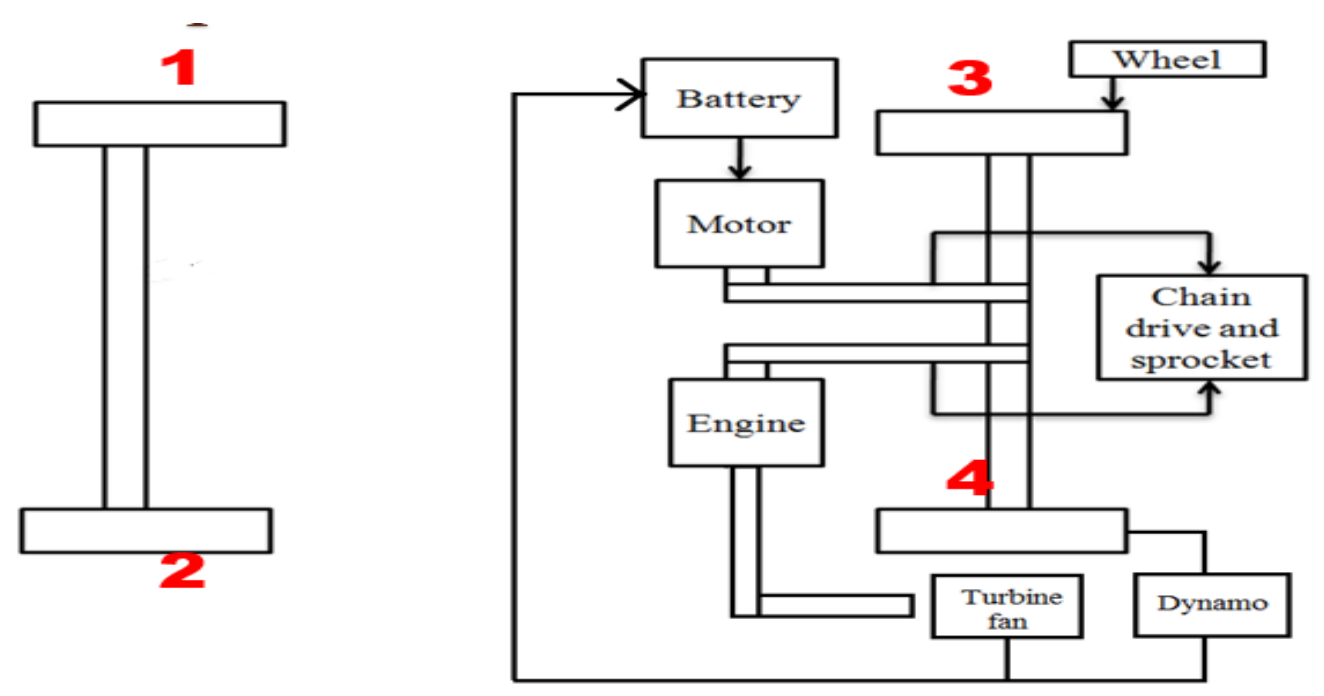

Fig.6. Proposed block diagram

In the proposed,shown in fig.6 we have successfully made a way for the motor to fit in into the system hence achieving the status hydrogen hybrid engine

\section{ALGORITHM FOR EXISTING SYSTEM}

1. Start the program

2. Check the battery level

3. Supply power to electrolysis process for hydrogen production from battery.

4. Hydrogen is supplied to the engine and the engine starts running.

5. Dynamo is used to start the battery when the vehicle is in motion.

6. Stop

\subsection{FLON CHART}

Fig 2.2:Flow Chart

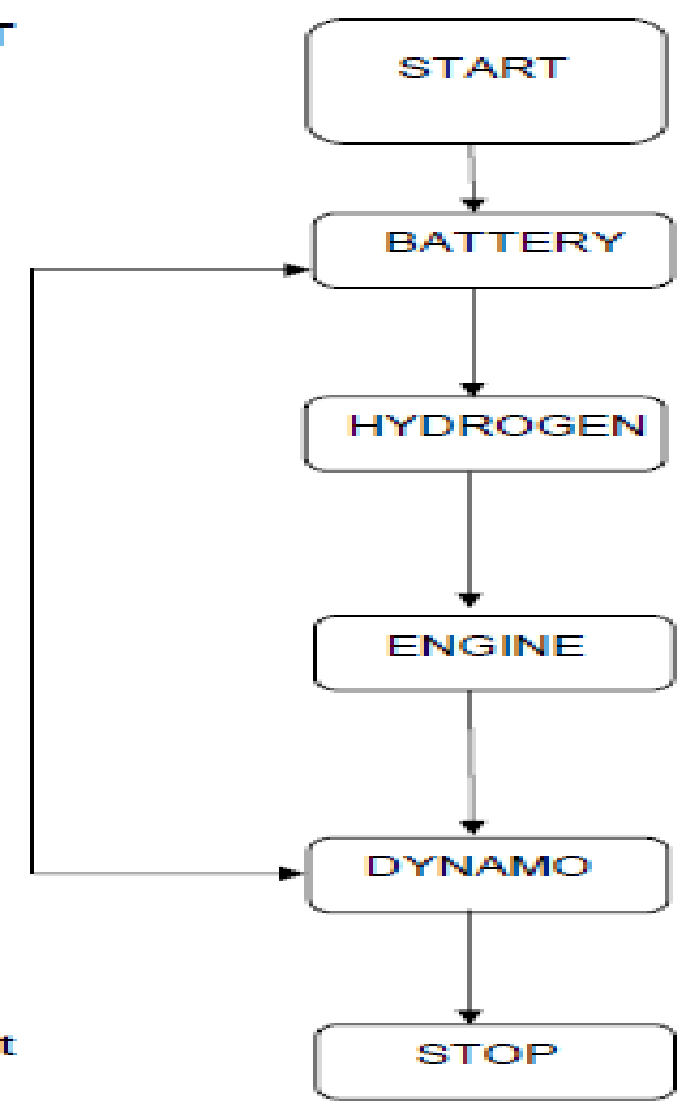

Fig.7.Flow chart of existing system 


\section{ALGORITHM FOR PROPOSED SYSTEM}

1. Start the program.

2. Choose whether you have to run the vehicle on engine or motor.

3. In motor check the battery charge, if the battery is low we can't run the motor so run the vehicle on petrol.

4. If the batteryis charged choose whether we have to send the supply to motor or to electrolysis process.

5. If the motor is chosen the vehicle runs on motor or if the engine is chosen the vehicle runs on hydrogen.

6. Thedynamo and turbine are used to charge the battery.

7. Stop

PROPOSED SYSTEM FLOW CHART

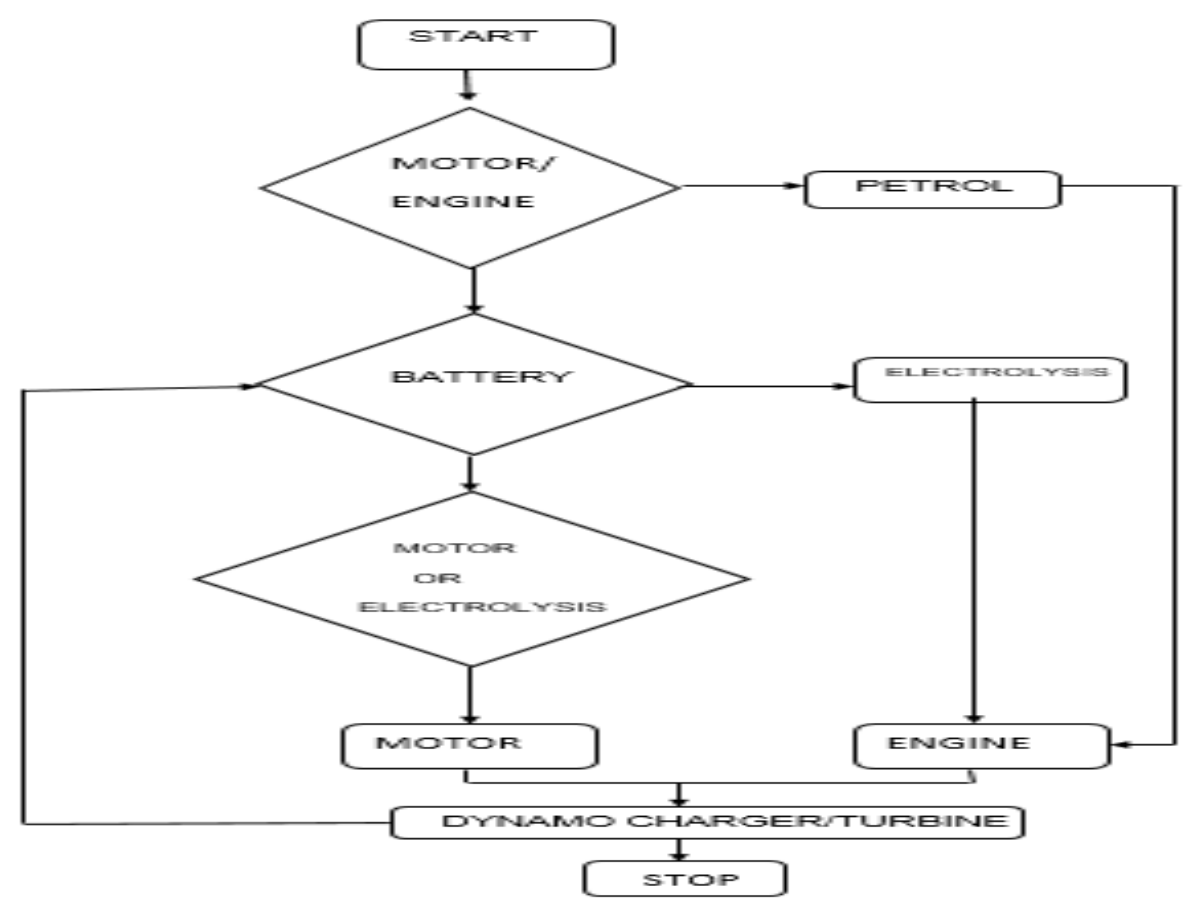

Fig.8.Flow chart for proposed system

\section{Conclusion}

Hydrogen is non-toxic andis far more efficient than other sources of energy, because it causes less pollution and significantly increases the Torque and horse power.it gives about $50 \%$ to60\%better mileage in highways and $30 \%$ to $35 \%$ better mileage in city.

Hybrids use less gasoline, and therefore emit less greenhouse gas. Built from Light Materials lighter, which means less energy is required to run

\section{Applications}

It is used in Fuel celled power transportation such as trucks, buses. Marine applications can also benefit from hybrid technology.

It can also be used in aerial lift truck to reduce emissions, fuel consumption, and audible noise, Used in the hydraulic lift mechanism

\section{References}

[1] Meenakshi, V., FemilaRoseline, J., Bharathi, M.L,'Design of led street lighting using arduino' journal of Advanced Research in Dynamical and Control Systems January 2019 
[2] Fathima KR, Bharathi ML. A novel grid integration scheme for the hybrid electric power generation using solar and wind energy resources. In2017 International Conference on Computation of Power, Energy Information and Commuincation (ICCPEIC) 2017 Mar 22 (pp. 599-609). IEEE.

[3] Bharathi ML, Kirubakaran D. Neural Network Controlled High-Step Up Based Single-Phase PV Inverter System with Improved Dynamic Response. Journal of Computational and Theoretical Nanoscience. 2017 Jan 1;14(1):421-9.

[4] Bharathi ML, Kirubakaran D. Fuzzy logic controlled PV supported triple stage ILBC converter system with improved dynamic response. In2017 International Conference on Computation of Power, Energy Information and Commuincation (ICCPEIC) 2017 Mar 22 (pp. 592-598). IEEE.

[5] Basha RF, Bharathi ML. A Wind Energy Supported DSTATCOM for Real and Reactive Power Support for a Linear Three-Phase Industrial Load. InInternationalConference on Intelligent Computing and Communication 2019 Jun 7 (pp. 755-767). Springer, Singapore

[6] Ramya D, mary Antony AS. A reconfigurable five/seven level inverter with reduced switching losses. In2017 International Conference on Computation of Power, Energy Information and Commuincation (ICCPEIC) 2017 Mar 22 (pp. 656-659). IEEE.

[7] Ramya D, Antony AS, Immanuel DG, Nagarajan G. Design of interleaved flyback converter. International Journal of Intelligent Enterprise. 2019;6(1):59-76.

[8] Ramya D, Antony AS, Immanuel DG. Development of high with suitable hysteresis for automatic voltage regulator. International Journal of Innovative technology and Exploring Engineering.2019:2278-3075,Vol 8 
